\title{
Use of waste materials in rubber matrix
}

\author{
Mariana Pajtášová ${ }^{1, *}$, Zuzana Mičicová $^{1}$, Darina Ondrušová ${ }^{1}$, Slavomíra Božeková ${ }^{1}$, \\ Róbert Janík ${ }^{1}$, Beáta Pecušová ${ }^{1}$, Lukáš Raník ${ }^{1}$ \\ ${ }^{1}$ Alexander Dubček University of Trenčín, Faculty of Industrial Technologies in Púchov, I. Krasku \\ 941/30, 02001 Púchov, Slovak Republic
}

\begin{abstract}
The presented paper deals with the use of waste materials as ecological fillers into rubber matrix. Waste materials were used as partial replacement of the commercial filler - carbon black, designated as N339. These prepared rubber compounds were characterized on the basis of the rheology and vulcanization characteristics - minimum torque $\left(\mathrm{M}_{\mathrm{L}}\right)$, maximum torque $\left(\mathrm{M}_{\mathrm{H}}\right)$, optimum time of vulcanization $\left(\mathrm{t}_{(\mathrm{c} 90)}\right)$, processing safety of compound $\left(\mathrm{t}_{\mathrm{s}}\right)$, rate coefficient of vulcanization $\left(\mathrm{R}_{\mathrm{v}}\right)$. In the case of the prepared vulcanizates, physical-mechanical properties (tensile strength, tensibility and hardness) and dynamic-mechanical properties (storage modulus, loss modulus, loss angle tan $\delta$ ) were investigated. Using the dependency of loss angle on temperature, the selected properties for tyre tread vulcanizates were evaluated, including traction on snow and ice, traction on the wet surface and rolling resistance.
\end{abstract}

Keywords: waste materials, filler, physical-mechanical properties, dynamicmechanical properties

\section{Introduction}

The rubber compounds are composed of polymers, fillers, oils, and numerous chemicals used for crosslinking or "vulcanization" of the compounds [1].

The fillers provide a large degree of strengthening of the rubber network, resulting in a substantial increase in stiffness, tensile strength, and resistance to abrasion [2].

The preparation of coffee leads to formation of relatively bulky waste in the form of coffee grounds and the most of these residues remain unutilized, being discharged to the environment, where they cause severe contamination and subsequent environmental pollution problems due to the toxic nature $[3,4]$.

In this study, we added the waste material - coffee extract into the rubber compounds in order to replace the conventional filler in an amount of $3 \mathrm{phr}$ with different granularity. We studied the rheological properties and vulcanization characteristics for non-vulcanized rubber compounds as well as physical-mechanical properties and dynamic-mechanical properties of resultant vulcanizates. The measured results were compared with values of standard.

\footnotetext{
* Corresponding author: mariana.pajtasova.fpt@gmail.com

Reviewers: Grzegorz Domek, František Nový
} 


\section{Experimental}

\subsection{Material}

The coffee extract was dried in dryer at temperature of $70{ }^{\circ} \mathrm{C}$ for $24 \mathrm{~h}$ to obtain the constant weight and then it was ground and filtered through a sieve with mesh size of $0.040,0.090$ and $0.200 \mu \mathrm{m}$.

\subsection{Preparation of rubber compounds}

The rubber compounds were prepared by two-step mixing process in laboratory mixer of Brabender type with chamber volume of $70 \mathrm{~cm}^{3}$ and $50 \mathrm{rpm}$ according to Slovak technical standards - STN 621425 [5]. The composition of fillers in compounds is shown in Table 1.

Table 1. The composition of fillers in compounds

\begin{tabular}{|c|c|c|c|c|c|}
\hline compounds & filler & $\mathbf{( p h r )}$ & filler & (phr) & $(\boldsymbol{\mu m})$ \\
\hline S & carbon black & 87 & coffee extract & - & - \\
\hline LC & carbon black & 84 & coffee extract & 3 & 0.040 \\
\hline MC & carbon black & 84 & coffee extract & 3 & 0.090 \\
\hline BC & carbon black & 84 & coffee extract & 3 & 0.200 \\
\hline
\end{tabular}

The rheological properties and vulcanization characteristics were determined using a MONSANTO 100 vulcameter. The samples $(8 \mathrm{~g})$ of the compounds were tested at the vulcanization temperature of $150{ }^{\circ} \mathrm{C}$ during $60 \mathrm{~min}$ and then, the rubber compounds were moulded at $150{ }^{\circ} \mathrm{C}$ according to optimum time of vulcanization $\left(\mathrm{t}_{\mathrm{c}(90)}\right)$.

\subsection{Preparation of vulcanizates}

Prepared vulcanizate test specimens in the shape of the double-sided blades were mechanically cut out from the vulcanized slabs. Five samples were prepared for the each vulcanizate. Tensile properties were measured using INSTRON universal testing machine. Hardness of prepared vulcanizates was measured by IRHD hardness tester with hardness ranging from 30 to 85 IRHD (International Rubber Hardness Degree). Dynamic-mechanical properties of the prepared vulcanizates were measured using DMA Q 800 (TA Instruments) - dynamic mechanical analyser at the temperature range between -70 and $70{ }^{\circ} \mathrm{C}$, at frequency of $1 \mathrm{~Hz}$ and at heating rate of $3{ }^{\circ} \mathrm{C} / \mathrm{min}$.

\section{Results and discussion}

\subsection{Rheology and vulcanization characteristics of rubber compounds}

The rheology and vulcanization characteristics - minimum torque $\left(\mathrm{M}_{\mathrm{L}}\right)$, maximum torque $\left(\mathrm{M}_{\mathrm{H}}\right)$, optimum time of vulcanization $\left(\mathrm{t}_{(\mathrm{c} 90)}\right)$, processing safety of compound $\left(\mathrm{t}_{\mathrm{s}}\right)$, rate coefficient of vulcanization $\left(\mathrm{R}_{\mathrm{v}}\right)$ of prepared rubber compounds are shown in graphical form in Figure 1-5. 


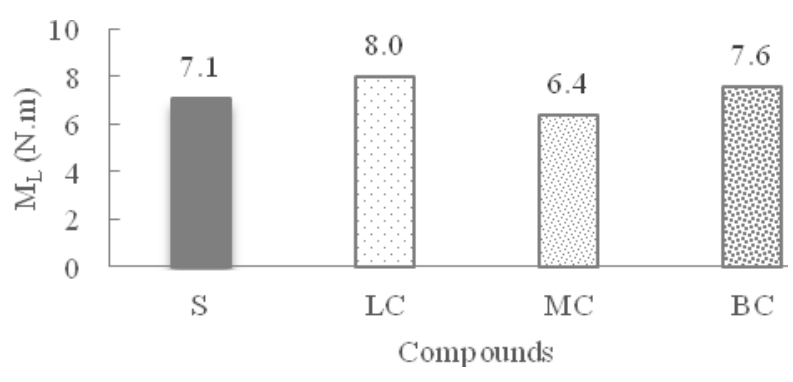

Fig. 1. Minimum torque of rubber compounds

The values of minimum torque for $\mathrm{LC}$ and $\mathrm{BC}$ rubber compounds are higher in comparison with standard compound. The increase of values of the minimum torque shows the higher stiffness as well as viscosity of the compounds at the beginning of vulcanization and it is probably due to good compatibility of rubber matrix with filler [6]. The MC rubber compound has lower value of minimum torque in comparison with standard compound.

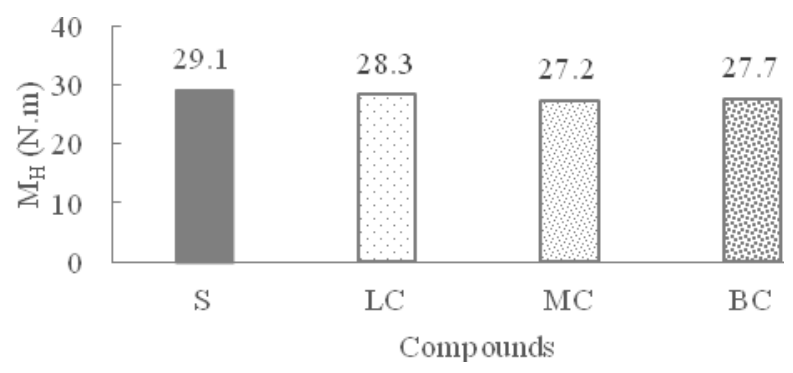

Fig. 2. Maximum torque of rubber compound

In the case of the maximum torque, all prepared rubber compounds exhibit lower values in comparison with standard compound.

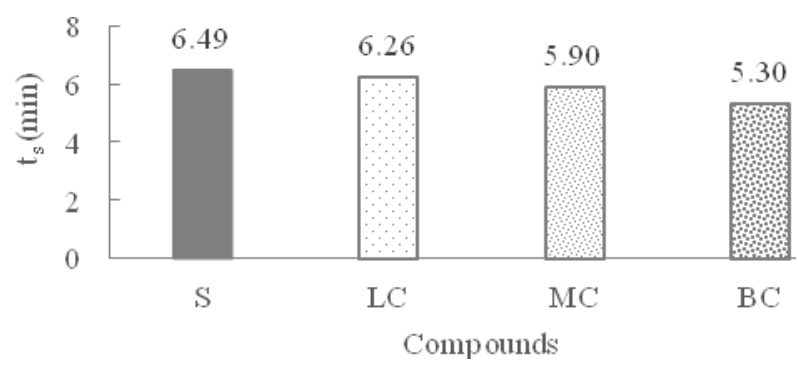

Fig. 3. Processing safety of compound

The resultant values of processing safety of compound for prepared rubber compounds are lower in comparison with standard compound. 


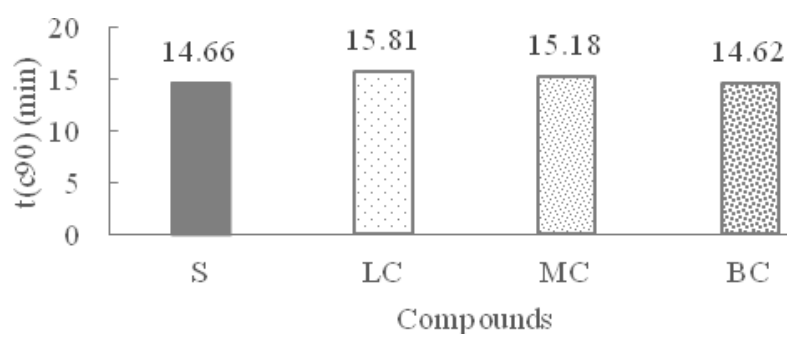

Fig. 4. Optimum time of vulcanization

From Figure 5, it can be seen, that BC rubber compounds has comparable optimum time of vulcanization to standard compound. The LC and BC rubber compounds exhibit higher values in comparison with standard compound. The extension of the optimum vulcanization time can be helpful for application in thick-walled rubber product, because the main purpose is to make vulcanization process slower [7].

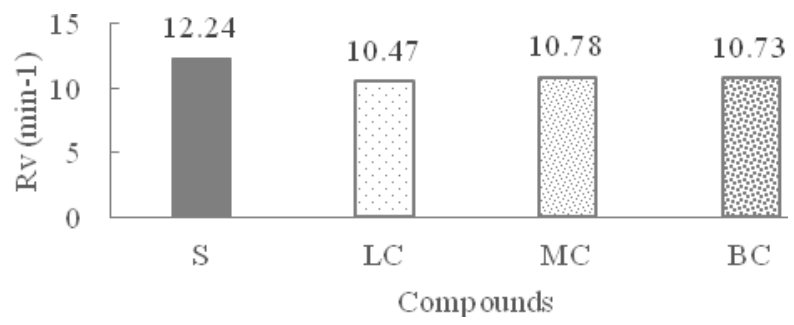

Fig. 5. Processing safety of compound

In the case of the processing safety of compound, all prepared rubber compounds exhibit lower values in comparison with standard compound.

\subsection{Physical-mechanical properties of rubber vulcanizates}

Selected physical and mechanical properties (tensile strength, tensibility and hardness) were tested and evaluated for standard vulcanizate and vulcanizates containing coffee extract with different grain size. Measured results of selected physical and mechanical properties are shown in graphical form in Figure 6,7 and 8.

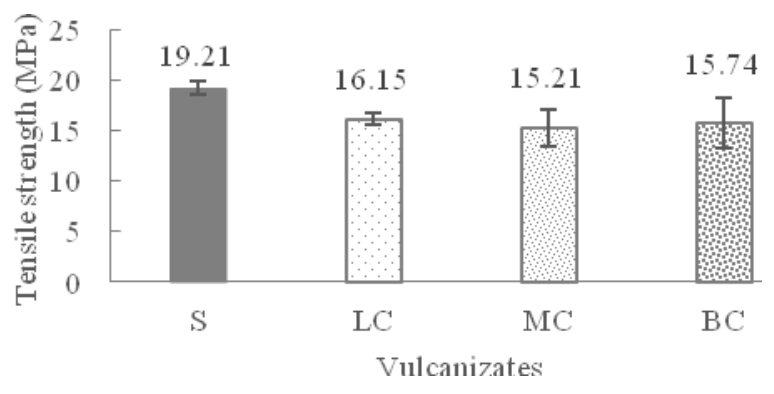

Fig. 6. Tensile strength of vulcanizates

From Figure 6, it can be seen, that all prepared vulcanizates show lower measured values of tensile strength in comparison with standard vulcanizate. 


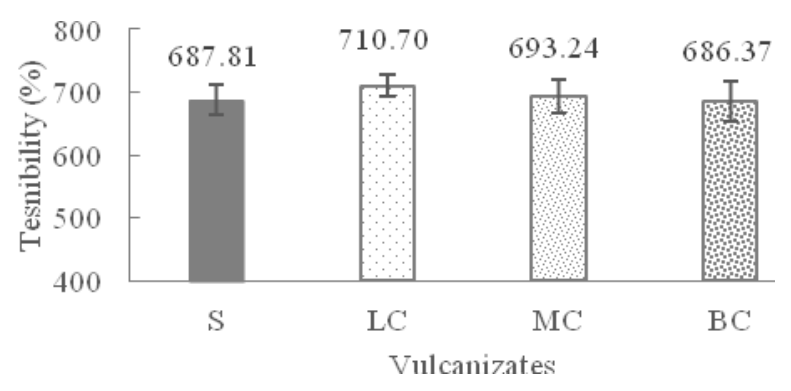

Fig. 7. Tensibility of vulcanizates

In the case of tensibility, LC and MC vulcanizate exhibit higher values in comparison with standard vulcanizate. On the other side, BC vulcanizate has comparable tensibility to standard vulcanizate.

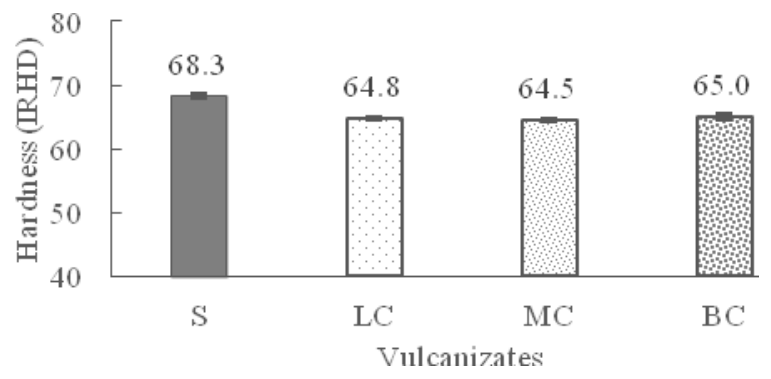

Fig. 8. Hardness of vulcanizates

The measured values of hardness for prepared rubber vulcanizates are lower in comparison with standard vulcanizate. The lower values of hardness indicate good incorporation of the filler into the compound and good compatibility with the rubber matrix [8].

\subsection{Dynamic-mechanical properties of rubber vulcanizates}

The viscoelastic behaviour of the prepared rubber vulcanizates was evaluated on the basis of the results of the dynamic-mechanical analysis measurements in the temperature range from $-70{ }^{\circ} \mathrm{C}$ to $70{ }^{\circ} \mathrm{C}$. The dependence of the dynamic-mechanical properties - the storage modulus ( $\left.E^{\prime}\right)$ and the loss modulus $\left(E^{\prime \prime}\right)$, the loss angle $(\tan \delta)$ on the temperature is graphically depicted in Fig. 9, 10 and 11. 


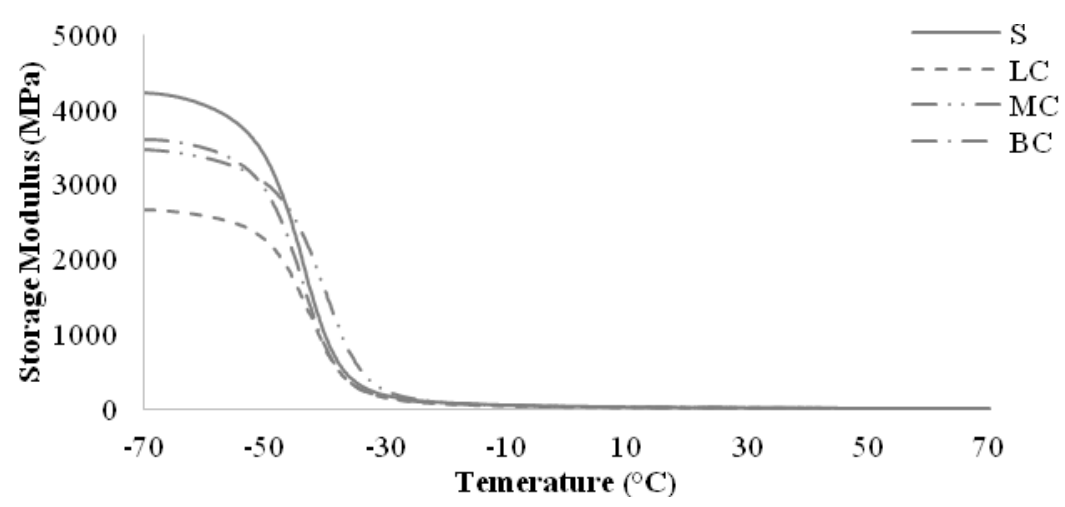

Fig. 9. Storage modulus of vulcanizates

As it is shown in Figure 9, the vulcanizates exhibit a decrease of the storage modulus in comparison with the standard vulcanizate in the following order: $\mathrm{LC}<\mathrm{MC}<\mathrm{BC}<\mathrm{S}$. These differences of the storage modulus ( $\left.E^{\prime}\right)$ are probably related to the different degree of interaction and dispersion between the waste material and the polymer matrix, where the lower storage modulus of the investigated vulcanizates exhibits better interaction at the interfacial interface and the filler dispersion $[9,10]$.

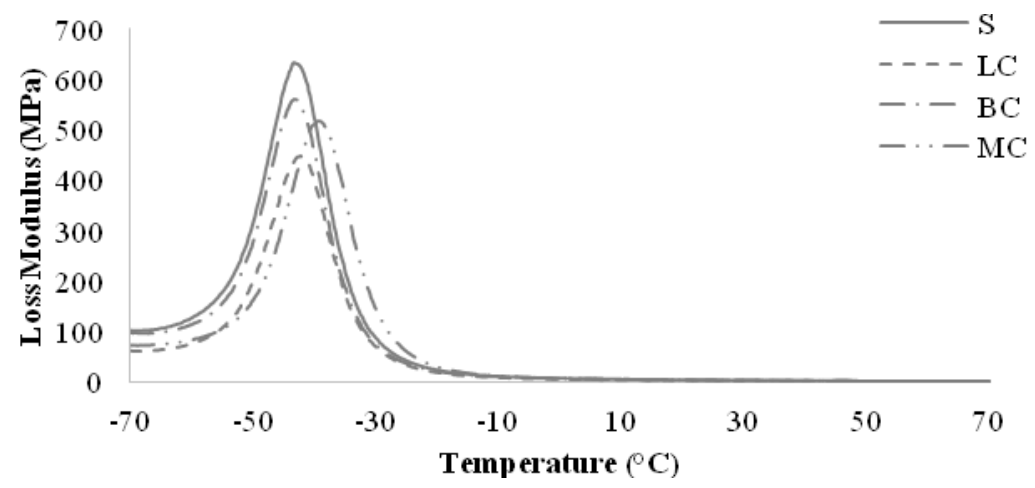

Fig. 10. Loss modulus of vulcanizates

The same course is observed for the loss modulus (E").

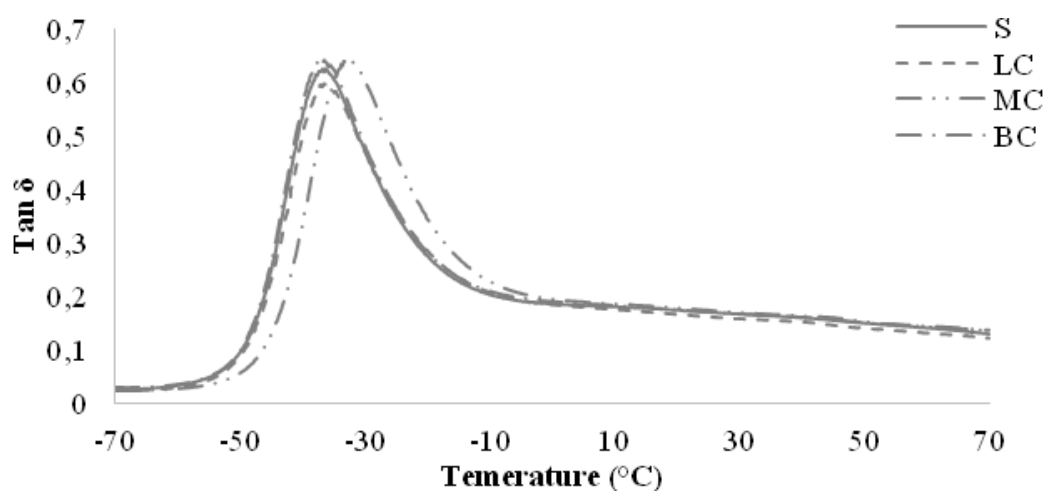

Fig. 11. Loss angle of vulcanizates 
The glass transition temperatures of the prepared rubber vulcanizates are determined from the maximum peaks of the loss angle $(\tan \delta)$. Their values are shown in Table 2.

Table 2. Tg and Tan $\delta$ results for vulcanizates

\begin{tabular}{|c|c|c|c|c|c|}
\hline Vulcanizates & $\operatorname{Tg}\left({ }^{\circ} \mathbf{C}\right)$ & $\tan \delta_{\text {MAX }}$ & $\begin{array}{c}\tan \boldsymbol{\delta} \\
(-25\end{array}$ & $\begin{array}{c}\tan \delta \\
\left(\mathbf{0}^{\circ} \mathbf{C}\right)\end{array}$ & $\begin{array}{c}\tan \delta \\
\left(\mathbf{6 0}^{\circ} \mathbf{C}\right)\end{array}$ \\
\hline $\mathrm{S}$ & -36.35 & 0.625 & 0.353 & 0.184 & 0.139 \\
\hline $\mathrm{LC}$ & -35.92 & 0.595 & 0.360 & 0.183 & 0.130 \\
\hline $\mathrm{MC}$ & -32.89 & 0.630 & 0.356 & 0.185 & 0.140 \\
\hline $\mathrm{BC}$ & -36.52 & 0.631 & 0.455 & 0.190 & 0.139 \\
\hline
\end{tabular}

The stiffening effect of the filler can be determined from the max. peak of $\operatorname{tg} \delta$. If the max. peak of $\tan \delta$ is lower, the stiffening of the resulting material is the better [11]. Values of max. peak of $\tan \delta$ decrease for vulcanizates in the following order: $\mathrm{LC}<\mathrm{S}<\mathrm{MC}<\mathrm{BC}$. The best stiffening can be assumed for vulcanized LC.

Based on the dependency of loss angle ( $\tan \delta$ ) on temperature, the selected properties for tyre tread vulcanizates were evaluated, including traction on snow and ice, traction on the wet surface and rolling resistance [12].

Tan $\delta$ for $-25{ }^{\circ} \mathrm{C}$ represents the traction on snow and ice. The $\mathrm{BC}$ vulcanizate exhibits best traction on snow and ice in comparison with standard vulcanizate. Tan $\delta$ for $0{ }^{\circ} \mathrm{C}$ represents traction on the wet surface. The $\mathrm{BC}$ vulcanizate exhibits best traction on the wet surface in comparison with standard vulcanizate. Tan $\delta$ for $60{ }^{\circ} \mathrm{C}$ represents the rolling resistance. The LC vulcanizate exhibits the best rolling resistance in comparison with standard vulcanizate.

\section{Conclusion}

The main aim of the paper was to investigate effect of the waste materials - coffee extract in rubber matrix. According to the results of rheological properties and vulcanization characteristics, physical-mechanical properties and dynamic-mechanical properties, we can conclude that carbon black can be replaced partially by fillers based on investigated waste materials. The best achieved values in properties were observed in the case of LC vulcanizate.

This work was supported by the Slovak Grant Agency KEGA 007TnUAD-4/207, VEGA 1/0589/17, VEGA $1 / 0649 / 17$ and resulted from the project "Center for quality testing and diagnostics of materials", ITMS code 26210120046 relating to the Operational Program Research and Development funded from European Fund of Regional Development.

\section{References}

1. L.N. Carli, O. Bianchi, R.S. Mauler, J.S. Crespo, Crosslinking kinetics of SBR composites containing vulcanized ground scraps as filler. Polym. Bull. 67, 1621-1631 (2011)

2. Z. Mičicová, M. Pajtášová, S. Domčeková, D. Ondrušová, L. Raník, T. Liptáková, Inorganic materials and their use in polymeric materials. Procedia Engineering 136, 239-244 (2016)

3. M. Haile, Integrated volarization of spent coffee grounds to biofuels. Biofuel Research Journal 2, 65-69 (2014) 
4. M. C. Echeverria, M. Nuti, Valorisation of the Residues of Coffee Agro-industry: Perspectives and Limitations. The Open Waste Management Journal 10, 13-22 (2017)

5. STN 62 1425: Raw rubber. A preparation of rubber compounds. 1984 [in Slovak]

6. D. Ondrušová, S. Domčeková, M. Pajtášová, A. Dubec, Z. Mičicová, B. Pecušová, Alternative filler based on the waste from glass production and its effect on the rubber properties. Procedia Engineering 177, $462-469$ (2017)

7. A. V. Chapman, A. J. Tinker, Vulcanization of Blends - Crosslink Distribution and its Effect on Properties. KGK-Kautschuk Gummi Kunstsoffe 56, 533-544 (2003)

8. D. Ondrušová, M. Pajtášová, Rubber components and their influence on rubber properties and environmental aspects of production. (Spolok Slovákov v Pol'sku, Krakow, 166 p., 2011) ISBN 978-83-7490-358-1

9. M. Bhattacharya, A. K. Bhowmick, Synergy in carbon black-filled natural rubber nanocomposites. Part I: Mechanical, dynamic mechanical properties, and morphology. Journal of Materials Science 45, 6126-6138 (2010)

10. A. Das, R. Jurk, K. Werner Stöckelhuber, G. Heinrich, Effect of Vulcanization Ingredients on the Intercalation-Exfoliation Process of Layered Silicate in an Acrylonitrile Butadiene Rubber Matrix. Macromolecular Materials and Engineering 293, 479-490 (2008)

11. A. Gantowski, P. Palutkiewicz, E. Boceąga, Numerical analysis of stress state during single point bending in DMTA examination. Journal of Achievements in Materials and Manufacturing Engineering 28, 47-50 (2008)

12. S. Božeková, Z. Mičicová, D. Ondrušová, M. Pajtášová, Vplyv modifikovaného alternatívneho plniva silánom Bis3-(triethoxysilyl)-tetrasulphid na vlastnosti gumárenských zmesí. Hutnické listy 5, 48-52 (2016) 